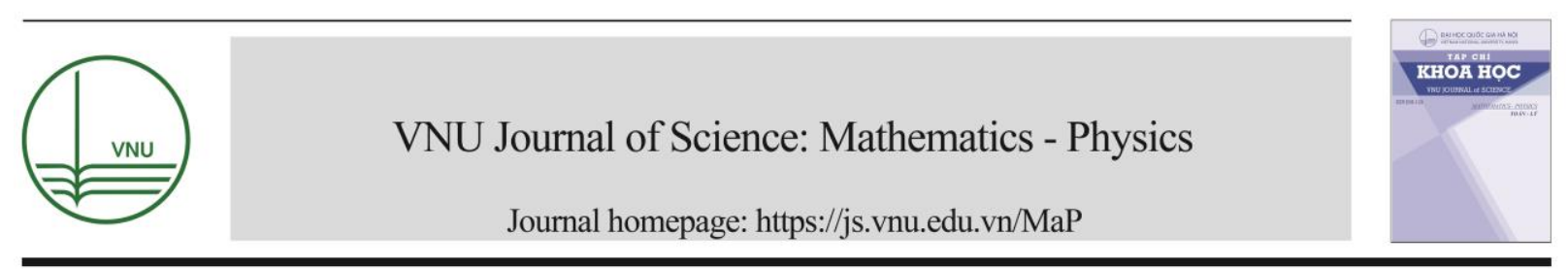

\title{
Blue, Green and Yellow Emissions at the Same Time from Mn-doped ZnS Microbelts
}

\author{
Nguyen Van Nghia ${ }^{1,2, *}$, Nguyen Duy Hung ${ }^{1}$ \\ ${ }^{1}$ Advanced Institute of Science and Technology (AIST), \\ Hanoi University of Science and Technology (HUST), 01 Dai Co Viet, Hanoi, Vietnam \\ ${ }^{2}$ Thuy Loi University, 175 Tay Son, Dong Da, Hanoi, Vietnam
}

Received 23 July 2017

Revised 22 September 2017; Accepted 27 September 2017

\begin{abstract}
An investigation of the morphology, structure, composition and optical properties of $\mathrm{ZnS}: \mathrm{Mn}^{2+}$ microbelts grown by the thermal evaporation method using $\mathrm{ZnS}$ powder and $\mathrm{MnCl}_{2} \cdot 4 \mathrm{H}_{2} \mathrm{O}$ powder as precursor materials is presented. The SEM images of the products show that $\mathrm{ZnS}: \mathrm{Mn}^{2+}$ microbelts are bigger and shorter than $\mathrm{ZnS}$ microbelts. EDS reveals that the composition of the microbelts include $\mathrm{Zn}, \mathrm{S}, \mathrm{O}, \mathrm{Mn}$ and $\mathrm{Cl}$ elements. The atom rate of oxygen composition of the doped microbelts seems to be slightly lower than undoped ones. XRD pattern of the prepared microbelts shows that $\mathrm{ZnO}$ coexists with $\mathrm{ZnS}$ on the undoped microbelts. However, at the Mn-doped microbelts, the component phase of $\mathrm{ZnO}$ is disappeared. Photoluminescence spectra of undoped $\mathrm{ZnS}$ microbelts reveal a strong broad emission band at visible wavelength region and a weak ultraviolet band. Interestingly, when $\mathrm{Mn}^{2+}$ is doped into the microbelts, the visible emission band is separated into blue, green, and yellow bands peaking at around $442,520 \mathrm{~nm}$, and $572 \mathrm{~nm}$, respectively. The effects of $\mathrm{Mn}^{2+}$ ions on the emission bands are discussed in detail.
\end{abstract}

Keywords: $\mathrm{ZnS}: \mathrm{Mn}^{2+}$ microbelts, photoluminescence, thermal evaporation.

\section{Introduction}

ZnS, an II-VI semiconductor, has been extensively investigated due to its potential applications in optics, photoelectronics, sensors, catalysts and so on [1-3]. Recently, numerous efforts have been employed to control the fabrication of micro and nanomaterials with various morphologies, since the novel properties and potential applications of nanomaterials depend sensitively on their shapes and sizes [4]. Because of doping $\mathrm{ZnS}$ with different metal ions, novel characteristics, such as stable and

\footnotetext{
* Corresponding author. Tel.: 84-984915472.

Email: nghiaaist@gmail.com

https//doi.org/ 10.25073/2588-1124/vnumap.4212
} 
tunable optical properties, could be obtained [5-7]. Among them, Mn-doped ZnS nanocrystals have been receiving much attention due to their promising application in optoelectronic devices [8]. A large number of Mn-doped $\mathrm{ZnS}$ nanocrystals with simple morphologies, such as thin film, nanowires, and nanorods have been prepared by various techniques [9-11]. The most reports of Mn-doped $\mathrm{ZnS}$ focused on the emission due to ${ }^{4} \mathrm{~T}_{1} \rightarrow{ }^{6} \mathrm{~A}_{1}$ transition within the $3 \mathrm{~d}$ shell of $\mathrm{Mn}^{2+}$. Usually, Mn-doped $\mathrm{ZnS}$ structures have two emission bands, one yellow-orange band of $\mathrm{Mn}^{2+}$ and the other of $\mathrm{ZnS}$ host material. In our work, we synthesize Mn-doped $\mathrm{ZnS}$ microbelts by thermal evaporation and report on their photoluminescence properties with three different peaks in visible region to demonstrate that the $\mathrm{Mn}$ concentration plays an important role in tuning the emission of radiative centers in $\mathrm{ZnS}$ microbelts.

\section{Experiment}

The undoped and Mn-doped $\mathrm{ZnS}$ microbelts were synthesized on silica substrates by thermal vapor deposition in a conventional horizontal quartz tube furnace. $\mathrm{ZnS}$ powder and a mixing of highpurity $\mathrm{ZnS}$ and $\mathrm{MnCl}_{2} \cdot 4 \mathrm{H}_{2} \mathrm{O}$ powders as the precursor materials were placed into an alumina boat and positioned at the center zone of the horizontal tube furnace. Silica substrates with size of $0.5 \times 0.5 \mathrm{~cm}$ were placed in the low temperature zone at about $20 \mathrm{~cm}$ downstream from the aluminum boat. A haft of the quartz tube containing the aluminum boat and silica substrates was setup outside the tube furnace until the furnace was heated to deposition temperature. The quartz tube was pumped down to pressure of $1 \times 10^{-3}$ Torr and heated to $300^{\circ} \mathrm{C}$, then the high-purity argon was introduced into the tube and the mechanical rotary pump was turn off. The flow rates of Ar were controlled by a mass flow meter at $160 \mathrm{sccm}$. The temperature of the furnace was raised continually to growth temperature at a ramping rate of $10{ }^{\circ} \mathrm{C} / \mathrm{min}$. The deposition temperature was set up at $1100{ }^{\circ} \mathrm{C}$. When temperature of the furnace increased to $900{ }^{\circ} \mathrm{C}$, the part of quartz tube containing the aluminum boat and silica substrates was pushed into the furnace to grow microbelts. During synthesis the furnace temperature was maintained at growth temperature for $30 \mathrm{~min}$, after that the furnace was allowed to cool naturally to room temperature.

\section{Results and discussion}

In order to study the morphology of the structures, FESEM were employed. Fig. 1 shows a series of FESEM images of the microstructures grown on silica substrates. A typical FESEM image shows that undoped $\mathrm{ZnS}$ microbelts are high density with several hundred nanometers to about one micron in widths and tens of microns in lengths (Fig. 1a). These microbelts are quite smooth and randomly oriented. For $\mathrm{Mn}$-doped $\mathrm{ZnS}$, the microstructures turned into bigger and shorter microbelts. Furthermore, the density of the microbelts seems to be reduced and the surface of them is rough with some black dots in it. The corresponding EDS spectra reveal that the undoped microbelts mainly contain $\mathrm{Zn}, \mathrm{S}$ and $\mathrm{O}$ elements and the atom ratio of undoped $\mathrm{ZnS}$ is 47.5, 36.5 and 16.0 at\%. The origin of $\mathrm{O}$ atom may come from reaction between $\mathrm{ZnS}$ and $\mathrm{O}_{2}$ which exist in the furnace tube and are not pumped to low enough pressure. For $\mathrm{Mn}^{2+}$ doped microbelts, the atom ratio of oxygen reduces a little to around $15.4 \%$. Also, the $\mathrm{Cl}$ and $\mathrm{Mn}$ components appear with atom ratios of about $10.6 \%$ and $1.6 \%$ respectively for the doped products. The $\mathrm{Cl}$ composition can exist on the microbelts due to reaction between $\mathrm{Zn}$ and $\mathrm{Cl}$ to form $\mathrm{ZnCl}_{2}$. 

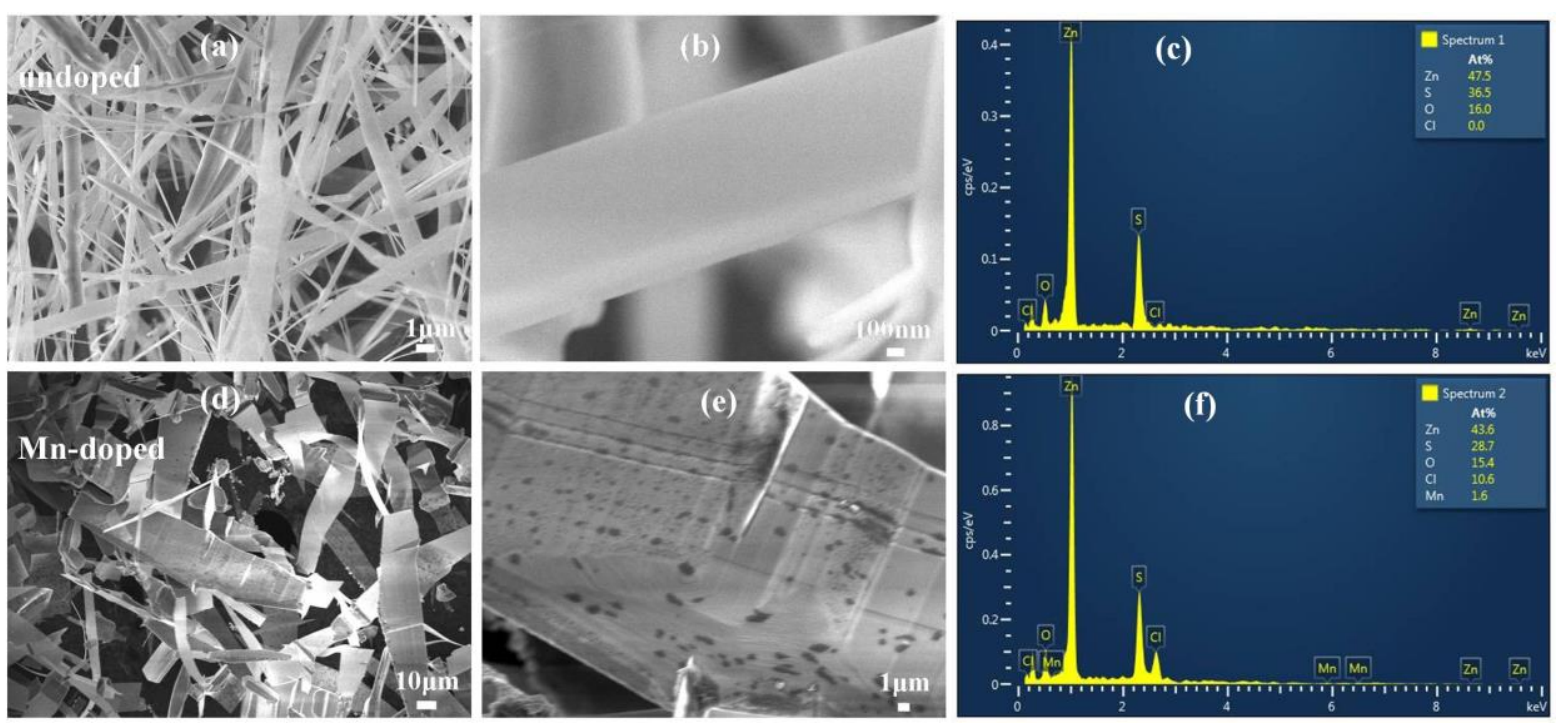

Figure 1. FESEM images with low and high magnification and EDS of undoped ZnS microbelts (a,b,c), and Mn-doped $\mathrm{ZnS}$ microbelts (d,e,f).

Furthermore, XRD measurement was performed in order to determine the crystalline phase of the microstructures. It is clear from Figure 2 that all of microbelts doped or undoped $\mathrm{Mn}$ are matched to the structure of wurtzite (JCPDS 05-0492). In detail, the XRD pattern of the undoped microbelts shows the $\mathrm{ZnO}$ peaks beside the main phase of $\mathrm{ZnS}$. The phase of $\mathrm{ZnO}$ is matched to the structure of wurtzite (JCPDS no.36-1451). The XRD pattern of undoped sample matched well with EDS analysis above, in which, there are $\mathrm{Zn}, \mathrm{S}$, and $\mathrm{O}$ elements at the same time. However, at Mn-doped $\mathrm{ZnS}$ microbelts, only $\mathrm{ZnS}$ phase is detected and no phase related to $\mathrm{Mn}$ or $\mathrm{Cl}$ being observed in XRD patterns. The reason of that may be due to the concentration of $\mathrm{Mn}$ or $\mathrm{Cl}$ in the microbelts is too small and XRD measurements cannot recognize the presence of them in the microbelts. The phase of $\mathrm{ZnO}$ disappeared in XRD pattern of these microbelts may be due to Mn prevented O from combining with $\mathrm{Zn}$ and $\mathrm{S}$ elements.

To investigate the optical propertie of the structures, the PL spectra of undoped and Mn-doped $\mathrm{ZnS}$ microbelts were measured at room temperature using a $275-\mathrm{nm}$ excitation wavelength as shown in Fig. 3. From this figure, for the undoped sample, PL spectrum shows two emission bands at ultraviolet and visible regions. The ultraviolet band is due to band to band transition of $\mathrm{ZnS}, \mathrm{ZnO}$ or $\mathrm{ZnOS}[12,13]$. The blue band peaking at $493 \mathrm{~nm}$ may be associated with point defects such as the isolated $\mathrm{Zn}$ vacancies in the single negative charge states or other oxygen-related centers of selfactivated or interstitial sulphur impurities $[1,14,15]$. However, in the visible emission band, the doped Mn microbelts show three peaks, at $442 \mathrm{~nm}$ (blue), $520 \mathrm{~nm}$ (green), and $572 \mathrm{~nm}$ (yellow). Morever, the UV emission band has a trend to be quenched. The blue emission band at around $442 \mathrm{~nm}$ is attributed to the surface defects such as sulfur vacancy or sulfur interstitial lattice defects $[2,3,5]$. Meanwhile, the green emission at around $520 \mathrm{~nm}$ may be assigned to the surface defects such as oxygen vacancies [16]. The yellow emission at around $572 \mathrm{~nm}$ is associated with the ${ }^{4} \mathrm{~T}_{1}-{ }^{6} \mathrm{~A}_{1}$ transition within the $3 \mathrm{~d}$ shell layer of $\mathrm{Mn}^{2+}[18,19,20]$. 


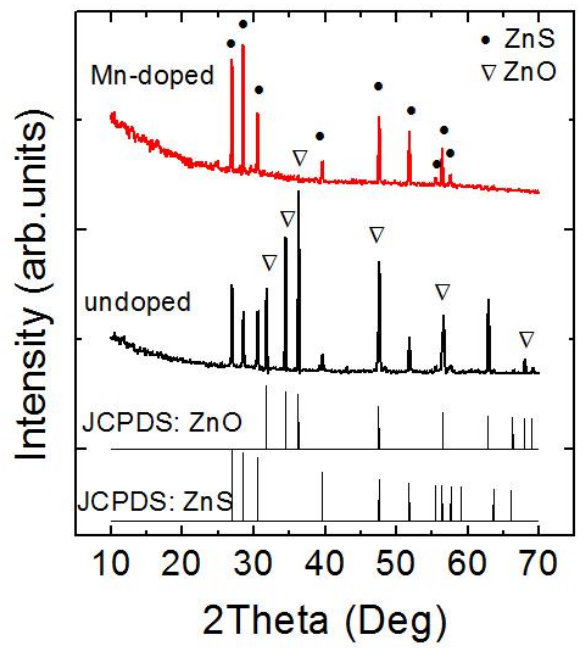

Figure 2. XRD pattern of $\mathrm{ZnS}$ and $\mathrm{Mn}$-doped $\mathrm{ZnS}$ microbelts grown on silica substrates.

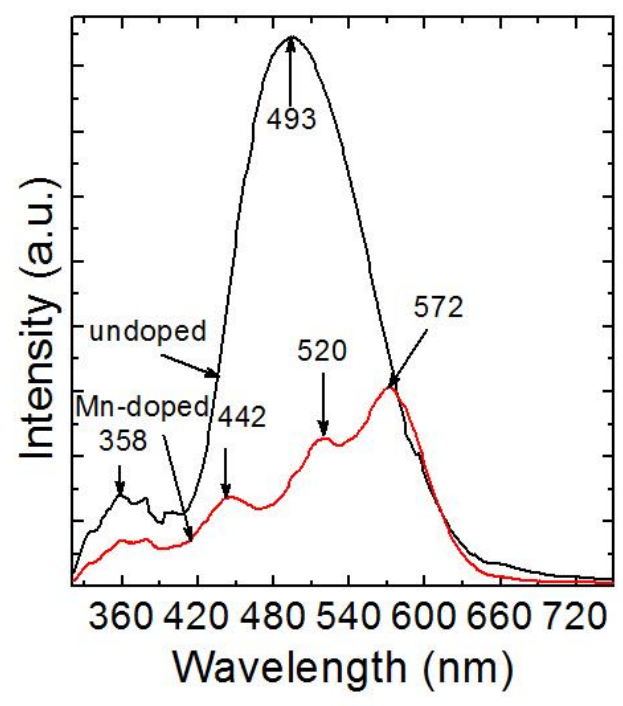

Figure 3. PL spectra of undoped and Mn-doped $\mathrm{ZnS}$ microbelts.

Furthermore, the effect of $\mathrm{Mn}$ on the radiative centers of $\mathrm{ZnS}$ microbelts are investigated by analysing the PLE spectra shown in Figure 4. In fact, excitation pathway for the emission of $\mathrm{Mn}^{2+}$ in the microbelts has two ways, namely the energy transfers directly from the $\mathrm{ZnS}$ host and another from the radiative defects to the $3 \mathrm{~d}$ states of $\mathrm{Mn}^{2+}$ [7]. The PLE measurements monitored at the emission wavelength of $570 \mathrm{~nm}$. At undoped sample, the spectra show that the microbelts are absorbed strongly at about $345 \mathrm{~nm}$ to $376 \mathrm{~nm}$ which are corresponded with the bandgap of $\mathrm{ZnS}, \mathrm{ZnO}$ or $\mathrm{ZnOS}$ [12], [21]. However, at the Mn-doped ZnS microbelts, there is a PLE peak at around $337 \mathrm{~nm}$ corresponding to 
band gap of $\mathrm{ZnS}(3.686 \mathrm{eV})$. The absorption edge was shifted to short wavelength, it means that the absorption related to the band to band transition of $\mathrm{ZnO}$ or $\mathrm{ZnOS}$ reduces when $\mathrm{Mn}$ is doped in $\mathrm{ZnS}$ host. These results show that $\mathrm{Mn}^{2+}$ modified the emission of the radiative centers of $\mathrm{ZnS}$ microbelts.

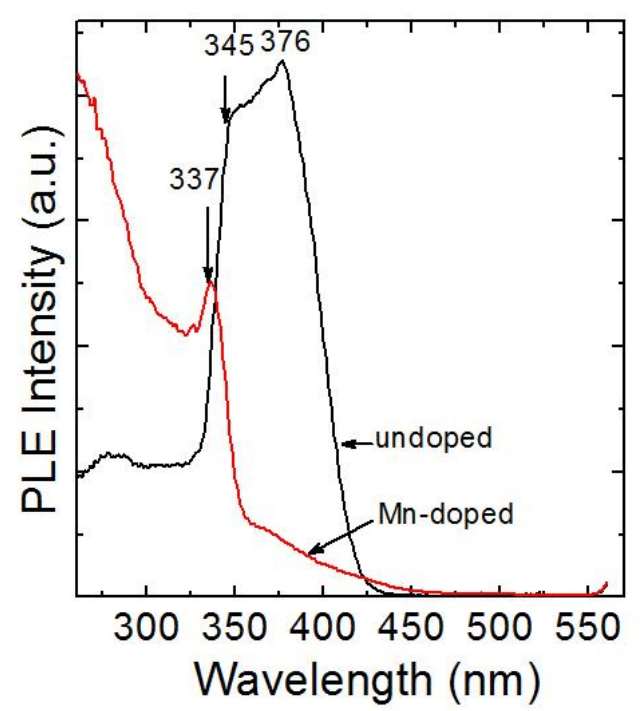

Figure 4. PLE spectra of undoped and Mn-doped $\mathrm{ZnS}$ microbelts.

\section{Conclusion}

The undoped and Mn doped ZnS microbelts on silica substrates have been successfully prepared by a thermal evaporation method. The undoped $\mathrm{ZnS}$ microbelts show a broad band emission at visible region around $493 \mathrm{~nm}$ which related to radiative centers of $\mathrm{ZnS}$ and $\mathrm{ZnO}$. By doping $\mathrm{Mn}$, the emission band of radiative centers related to $\mathrm{S}$ and $\mathrm{O}$ in the $\mathrm{ZnS}$ microbelts separated into blue, green, and yellow emissions. The UV emission band has a trend to be quenched at the Mn-doped sample. Therefore, the emission of radiative centers of $\mathrm{ZnS}$ can be controlled by $\mathrm{Mn}$ doped into $\mathrm{ZnS}$ microbelts.

\section{References}

[1] G. H. Yue et al., Hydrothermal synthesis of single-crystal ZnS nanowires, Appl. Phys. A Mater. Sci. Process., vol. 84, no. 4, (2006) 409.

[2] A. Goudarzi et al., Low-Temperature Growth of Nanocrystalline Mn-Doped ZnS Thin Films Prepared by Chemical Bath Deposition and Optical Properties, Chem. Mater., vol. 21, no. 12, (2009) 2375.

[3] W. W. G. Becker and A. A. J. Bard, Photoluminescence and photoinduced oxygen adsorption of colloidal zinc sulfide dispersions, J. Phys. Chem., vol. 78712, no. 24, (1983) 4888.

[4] T. T. Q. Hoa et al., Optical properties of Mn-doped ZnS semiconductor nanoclusters synthesized by a hydrothermal process, Opt. Mater. (Amst)., vol. 33, no. 3, (2011) 308.

[5] S. Wageh, Z. S. Ling, and X. Xu-Rong, Growth and optical properties of colloidal ZnS nanoparticles, J. Cryst. Growth, vol. 255, no. 3-4, (2003) 332.

[6] K. Sooklal, B. S. Cullum, S. M. Angel, and C. J. Murphy, Photophysical Properties of ZnS Nanoclusters with Spatially Localized Mn 2+, J. Phys. Chem., vol. 100, no. 11, (1996) 4551. 
[7] S. Sapra, A. Prakash, A. Ghangrekar, N. Periasamy, and D. D. Sarma, Emission properties of manganese-doped ZnS nanocrystals, J. Phys. Chem. B, vol. 109, no. 5, (2005) 1663.

[8] B. J. Ge, J. Wang, H. Zhang, X. Wang, Q. Peng, and Y. Li, Halide-Transport Chemical Vapor Deposition of Luminescent ZnS : Mn 2 + One-Dimensional Nanostructures, no. 2, (2005) 303.

[9] B. Y. Geng et al., Synthesis and photoluminescence properties of ZnMnS nanobelts, vol. 2157, (2004) 10.

[10] X. J. Hao, A. P. Podhorodecki, Y. S. Shen, G. Zatryb, J. Misiewicz, and M. A. Green, Effects of Si-rich oxide layer stoichiometry on the structural and optical properties of Si QD / $\mathrm{SiO}_{2}$ multilayer films, Nanotechnology, vol. 20, no. 48, (2009) 485703.

[11] W. Tang and D. C. Cameron, Electroluminescent zinc sulphide devices produced by sol-gel processing, Thin Solid Films, vol. 280, no. 1-2, (1996) 221.

[12] D. Q. Trung, N. Tu, N. D. Hung, and P. T. Huy, Probing the origin of green emission in 1D ZnS nanostructures, J. Lumin., vol. 169, (2016) 165.

[13] N. Kumbhojkar, V. V. Nikesh, A. Kshirsagar, and S. Mahamuni, Photophysical properties of ZnS nanoclusters, J. Appl. Phys., vol. 88, no. 11, (2000) 6260.

[14] John S. McCloy and Barrett G. Potter, Photoluminescence in Chemical Vapor Deposited ZnS: insight into electronic defects, OPTICAL MATERIALS EXPRESS, Vol. 3, No. 9, (2013) 1273.

[15] Ji-Hong Zhao, Chun-Hao Li, Jun-Jie Xu, Ya-Wei Hao, and Xian-Bin Li, Surface modification of nanostructured ZnS by femtosecond laser pulsing, Applied Surface Science 293 (2014) 332.

[16] H. Tang, B. J. Kwon, J. Kim, and J. Y. Park, Growth modes of ZnS nanostructures on the different substrates, J. Phys. Chem. C, vol. 114, no. 49, (2010) 21366.

[17] T. Mitsui, N. Yamamoto, T. Tadokoro, and S. Ohta, Cathodoluminescence image of defects and luminescence centers in ZnS/GaAs (100), J. Appl. Phys., vol. 80, no. 12, (1996) 6972.

[18] R. N. Bhargava, D. Gallagher, X. Hong, and A. Nurmikko, Optical Properties of Manganese-Doped of ZnS," Phys. Rev. Lett., vol. 72, no. 3, (1994) 1.

[19] Jitao Li, Kuili Liu, Xinying Zhu, Ming Meng, Wei Qin, Quantao Liu, and Chunxiang Xu, Competitive mechanism of electron transition in Mn-doped ZnS nanoribbons, Journal of Alloys and Compounds 658 (2016) 616.

[20] H.J. Yuan, X.Q. Yan, Z.X. Zhang, D.F. Liu, Z.P. Zhou, L. Cao, J.X. Wang,Y. Gao, L. Song, L.F. Liu, X.W. Zhao, X.Y. Dou, W.Y. Zhou, and S.S. Xie, Synthesis, optical, andmagnetic properties of $Z_{1-x} M_{x} S$ nanowires grown by thermal evaporation, Journal of Crystal Growth 271 (2004) 403.

[21] Ngo Xuan Dai, Do Thanh Long, Nguyen Ngoc Long, and Nguyen Thi Thuc Hien, Fabrication and Photoluminescence Properties of ZnS Nanoribbons and Nanowires, Journal of the Korean Physical Society, vol. 52 , no. 5, (2008) 1530. 